\title{
Making Healthy Places
}

Andrew L. Dannenberg, Howard Frumkin, and Richard J. Jackson 



\section{Making Healthy Places Designing and Building for Health, Well-being, and Sustainability}

Edited by

Andrew L. Dannenberg, Howard Frumkin, and Richard J. Jackson

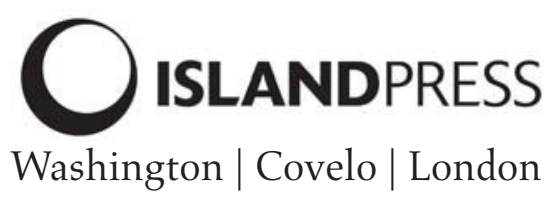


(C) 2011 Andrew L. Dannenberg, Howard Frumkin, and Richard J. Jackson All rights reserved under International and Pan-American Copyright Conventions. No part of this book may be reproduced in any form or by any means without permission in writing from the publisher: Island Press, Suite 300, 1718 Connecticut Ave., NW, Washington, DC 20009

ISLAND PRESS is a trademark of the Center for Resource Economics.

Library of Congress Cataloging-in-Publication Data

Making healthy places : designing and building for health, well-being, and sustainability / edited by Andrew L. Dannenberg, Howard Frumkin, and Richard J. Jackson.

p. $\mathrm{cm}$.

Includes bibliographical references and index.

ISBN-13: 978-1-59726-726-7 (hardback)

ISBN-10: 1-59726-726-0 (cloth)

ISBN-13: 978-1-59726-727-4 (paper)

1. Cities and towns-Growth-Health aspects. 2. City planning-Health aspects. 3. Sustainable development. 4. Urban health-Government policy. 5. Urban policy. I. Dannenberg, Andrew L. II. Frumkin, Howard. III. Jackson, Richard, 1945-

HT371.M27 2011

307.76 - dc23

2011020209

Printed using Aldus

Text design by Paul Hotvedt

Typesetting by Blue Heron Typesetters, Inc.

4

Printed on recycled, acid-free paper

Manufactured in the United States of America

10987654321

Note: The findings and conclusions cited in Chapters 1, 5, 6, 9, 12, 14, 15, 20, and 22 of this book are those of the authors and do not necessarily represent the views of the Centers for Disease Control and Prevention.

Keywords: air quality, biophilic design, community design, environmental health, green building, green communities, green schools, health care settings, injuries and the built environment, land use planning, mental health, physical activity, resiliency to disasters, social capital, transportation, urban agriculture, urban policy, vulnerable populations, walkable neighborhoods, water quality 




We dedicate this book to Kate, Joanne, and Joan, and to our children, Ned, Alice, Gabe, Amara, Brendan, Devin, and Galen, and to their children, and to their children's children.

We do not inherit the Earth from our Ancestors, we borrow it from our Children.

- Ancient proverb 



\section{Contents}

Preface

$\mathrm{XV}$

Richard J. Jackson

\section{Part I. Introduction}

Chapter 1

An Introduction to Healthy Places

Howard Frumkin, Arthur M. Wendel,

Robin Fran Abrams, and Emil Malizia

\section{Part II. The Impact of Community Design on Health}

Chapter 2

Community Design for Physical Activity

James F. Sallis, Rachel A. Millstein, and Jordan A. Carlson

Chapter 3

Food Environments

Carolyn Cannuscio and Karen Glanz 
Chapter 4

Community Design and Air Quality

Jonathan M. Samet

Chapter 5

Injuries and the Built Environment

David A. Sleet, Rebecca B. Naumann, and Rose Anne Rudd

Chapter 6

Community Design for Water Quantity and Quality

Lorraine C. Backer

Chapter 7

Mental Health and the Built Environment

William C. Sullivan and Chun-Yen Chang

Chapter 8

Social Capital and Community Design

Caitlin Eicher and Ichiro Kawachi

Chapter 9

Vulnerable Populations and the Built Environment

Chris S. Kochtitzky

\section{Part III. Diagnosing and Healing Our Built Environments}

Chapter 10

Transportation and Land Use

Reid Ewing, Gail Meakins, Grace Bjarnson, and Holly Hilton

Chapter 11

Healthy Homes

James Krieger and David E. Jacobs

Chapter 12

Healthy Workplaces

Donna S. Heidel, L. Casey Chosewood,

Matthew Gillen, Paul Schulte, Gregory Wagner,

Kenneth M. Wallingford, and Liz York

Chapter 13

Healthy Health Care Settings

Craig Zimring and Jennifer DuBose 
Chapter 14

Healthy Schools

Howard Frumkin and Jared Fox

Chapter 15

Contact with Nature

Howard Frumkin and Jared Fox

Chapter 16

Resiliency to Disasters

Timothy Beatley

\section{Part IV. Strategies for Healthy Places: A Toolbox}

Chapter 17

Behavioral Choices and the Built Environment Margaret Schneider

Chapter 18

Policy and Legislation for Healthy Places

Lisa M. Feldstein

Chapter 19

Community Engagement in Design and Planning Manal J. Aboelata, Leah Ersoylu, and Larry Cohen

Chapter 20

Measuring, Assessing, and Certifying Healthy Places

Andrew L. Dannenberg and Arthur M. Wendel

\section{Part V. Looking Outward, Looking Ahead}

Chapter 21

Training the Next Generation to Promote Healthy Places Nisha D. Botchwey and Matthew J. Trowbridge

Chapter 22

Healthy Places Research: Emerging Opportunities

Richard J. Jackson, Arthur M. Wendel,

and Andrew L. Dannenberg 
Urban Health in Low- and Middle-Income Countries Jennifer C. Johnson and Sandro Galea

Chapter 24

366

Built Environments of the Future

Anthony G. Capon and Susan M. Thompson

Glossary

About the Editors

397

Contributors

398

Acknowledgments

403

Index 


\title{
Preface
}

\author{
Richard J. Jackson
}

Ten years ago the editors of this book confronted a striking revelation: the manner in which we design and build our communities—-where we spend virtually our entire lives-has profound impacts on our physical, mental, social, environmental, and economic well-being. Nations of the twenty-first century are caught up in a perfect storm of intersecting health, environmental, and economic challenges: escalating health care and social costs, environmental threats from resource depletion and climate change, economic impacts associated with the "end of oil" and an aging population and workforce, and an inadequate educational approach that rests on and perpetuates silos of knowledge and disciplines. Because these challenges are interconnected, none can be addressed in isolation. We need system-level approaches that cross many disciplines and populations. We must rethink the ways in which our physical environments, homes, offices, neighborhoods, regions, and transit systems are designed and constructed, understand how they impact health, and ensure that they foster equity and sustainability. The purposes of this book are to explore these interconnected issues particularly as they are affecting the United States and, through multidisciplinary collaborations, to develop solutions that promote the well-being and vitality of our society.

More than ever before, Americans today are faced with poor nutrition and a lack of physical activity, both of which are leading to serious health consequences. Over the past few decades, obesity has become a major public health issue. 
Its prevalence has increased at a striking rate since the 1960s, when an estimated 45 percent of Americans were overweight or obese (CDC, National Center for Health Statistics 2009). Now, two out of every three American adults twenty years old or older are overweight or obese (Flegal 2010). Before 1985, among the states with data available, no state reported an adult obesity prevalence higher than 15 percent. In 2009, only one state-Colorado-had an obesity prevalence of less than 20 percent (CDC 2010b). Prevalence of obesity among US children and adolescents has tripled since the 1970s: between the late 1970s and 2008, obesity rates rose for six- to eleven-year-olds from 7 percent to 20 percent, and for adolescents from 5 percent to 18 percent (CDC 2010a). Overweight and obesity increase the risks of cancer, heart disease, stroke, high blood pressure, joint and bone disease, depression, birth defects, and other serious afflictions. From a population standpoint, the most fearsome complication of obesity is diabetes. Developing diabetes before the age of forty shortens life expectancy by about fourteen years and diminishes one's time with a good quality of life by twenty years (Narayan et al. 2003). Becoming morbidly obese (having a body mass index greater than 35) increases the risk of diabetes fortyfold for a man and one hundredfold for a woman. What is most striking is that if current trends are not reversed, today's young people could be the first generation of Americans to have a shorter average life span than their parents.

Since 2000, antidepressants have become the most prescribed medication in the United States, and the percentage of the population receiving them has doubled since the mid-1990s (Olfson and Marcus 2009). Our children are increasingly being medicated for inattentiveness or hyperactivity, with the percentage tripling between 1987 and 1997 (Olfson et al. 2003). Although exposure to regular physical activity in natural settings has been shown to be effective in reducing symptoms of childhood attention deficit hyperactivity disorder, more and more children confront environments hostile to walking, bicycling, and independent play and have limited access to greenspace (Kuo and Taylor 2004). Many teens and others unable to drive live in isolated housing developments without shops, community centers, or public transportation and are at increased risk of boredom and depression. Some newer housing developments provide improved amenities for young families, although many people still face limited access to walkable neighborhoods with local schools, parks, and retail.

The health threats we face cannot be countered by medical science alone. Although there are medicines to help us lose weight, they will never be as safe or as cheap as a good diet and exercise, particularly the incidental exercise that was a routine part of earlier generations' lives as they walked to shops, churches, and workplaces and climbed stairs in buildings. Bariatric surgery (sometimes called stomach stapling) and liposuction will never be cheap or totally safe. For 
depression, psychotherapy and antidepressants are medically useful but will never be as inexpensive as exercise and being with people who care about us. To decrease heart disease, cancer, osteoporosis, depression, and other diseases, we need convenient opportunities for regular physical activity. Exercise does not need to be done on a treadmill or "health club" machine; it is less costly and has the same benefits when spread throughout our day in the form of walking, stair climbing, and carrying packages. The trouble is that in the last half century, we have effectively engineered physical activity out of our daily lives.

Americans have made great strides in advancing technology and improving daily living conditions but are inefficient when it comes to health care. In 1960, the United States spent 5 percent of the gross domestic product on health care; in 2007, the portion was 16 percent-a staggering \$2.3 trillion (Orszag and Ellis 2007). Paradoxically, high health care spending does not guarantee better quality; rates of chronic diseases, including obesity and asthma, are increasing even as our medical spending increases. These increasing rates of illnesses and costs cannot be addressed within the medical sector alone. It is more important than ever before to invest in preventive measures that focus on efficiency, effectiveness, and equity. Putting the fundamental tenet of prevention into practiceand thus intervening before disease occurs, not when it already has-prevents suffering and saves money. This is an especially important consideration as the US population ages. The proportion of Americans age sixty-five and over is expected to increase from 12 percent in 2009 to nearly 20 percent in 2030, portending increased medical costs (Administration on Aging 2010). To prevent disease and improve quality of life for Americans of all ages, we must look "upstream" to how our food is produced, how we lay out our cities, and how we design our homes and buildings. Those who work and have expertise in these domains typically do not think of their professions as health related. The fact is, however, that health is determined by planning, architecture, transportation, housing, energy, and other disciplines at least as much as it is by medical care. It is our shared duty to work together to build communities that are safe, affordable, lively, and healthy.

The modern America of obesity, inactivity, depression, and loss of community has not "happened" to us; rather we legislated, subsidized, and planned it. Our taxes subsidized the highways that turned the downtowns of most American cities into no-man's lands (and certainly no-child's lands) and the countryside into sprawl. The elderly and those without the option of driving (the young, low-income, or disabled) have often lacked the option of living in a lively town center because they have been unable to find affordable housing or needed services there. We can, if we choose, legislate, subsidize, and plan for health promotion and disease prevention. For example, aggressive implementation of 
labor-intensive, urban, organic agriculture can create meaningful work, improve nutrition, reduce toxic chemical usage, lower greenhouse gas emissions, and offer green respite and good cuisine. However, we must have the master plans, the building codes, the tax policies, the knowledge, and the leadership to enact this kind of solution.

The challenges to the physical infrastructure of the United States are formidable. The United States accomplished its unspoken goal of having a car for every driver in the 1970s. From 1960 to 2000, Americans' per capita vehicle miles traveled doubled, from 4,000 to close to 9,000 miles per year, although this number has remained stable since 2000-perhaps because every urban area already feels full of cars (Litman 2010). Americans also spend more than one hundred hours per year commuting to work, which is more than the ten days of vacation time offered in many jobs (US Census Bureau 2005). Annual hours of highway traffic delay per person in urban areas increased from an average of twenty-one hours in 1982 to about fifty-one hours in 2007 (Texas Transportation Institute 2009). During that same time, rush hour increased from 4.5 hours of the day to 7 hours (US DOT, Federal Highway Administration 2008). Aspiring toward a future with a car for every driver makes little sense given that the US population will double by the end of this century. Nearly 600 million people will be vying for limited resources in our not-so-distant future, so we must undertake measures to develop a sustainable infrastructure now.

The editors of this book are physicians-one in family medicine, one in internal medicine, and one in pediatrics - and all three of us work in preventive medicine and public health. Our careers have been challenging; we have studied the health effects of air and water pollution, of infectious agents, of hazardous waste sites, and of pesticides and other toxic substances. As we examined the sources of air pollution, we noted that more than half of this pollution is related to energy use in buildings and more than a third to transportation. We investigated birth defects and other diseases related to contaminated water but have seen health leaders fail to examine how rapidly the water underground and in our streams is being polluted by the toxic materials that run off our parking lots into creeks, rivers, and eventually our drinking water. We have examined injury and death rates among bicyclists, pedestrians, and vehicle passengers from car crashes, yet only recently have public health leaders begun to study how the design of cities, suburbs, and rural areas impacts people.

At the turn of the millennium, conventional wisdom and marketing encouraged people to buy automobile-dependent tract homes distant from their workplaces. Though touted as a smart investment, this paradigm severely undermined the population's health and environment. When one of this book's authors, Richard Jackson, wrote about this phenomenon in a publication called 
Sprawlwatch, he was condemned by the housing industry and berated by members of Congress. The suggestion that the obesity epidemic was due not only to bad nutrition but also to severe car dependency was even derided by some of our public health colleagues. Today these outlandish ideas are recognized as common sense and are regularly cited by the US president, by major policy organizations, and in legislation as ways to address outcomes associated with the built environment. There is now good evidence showing that people who use public transit for their daily commutes weigh less and are healthier (MacDonald et al. 2010). Communities that support transit use, walking, and bicycling are associated with improved air quality (Frank, Stone, and Bachman 2000; Frank et al. 2006), reduced greenhouse gas emissions (Ewing et al. 2008), lower rates of traffic injuries (Ewing, Schieber, and Zegeer 2003; Dumbaugh 2005), more physical activity (LaChapelle and Frank 2009), and lower body weights (LaChapelle and Frank 2009), thus reducing the likelihood of chronic disease. The issue of neighborhood design dictating children's physical and social development has become prominent; the American Academy of Pediatrics has issued clinical guidance to this effect (Committee on Environmental Health 2009). Banks and insurers are also increasingly aware of neighborhood "livability." In the recent decline of the housing market, the places that best held their values were dense areas that offered walking, local parks, and nearby retail and transit. The high costs of gasoline and owning a car are leading many families to choose to own only one car or even no cars. Bicycling has seen a resurgence for reasons of health, economics, and sustainability, although the infrastructure for safe bicycling has not kept pace. Recent high-level commitments by the US Department of Transportation to provide more support for nonmotorized transportation options offer hope for an increase in safe routes to school, trails, bicycle routes, transit options, and other important ways to improve health and reduce pollution and traffic risks. Since we published the forerunner of this book-Urban Sprawl and Public Health-in 2004, enormous progress has been made in the field of healthy community design. Still, much work remains to be done.

Although we have a strong focus on health, our work is also fundamentally rooted in the notion of sustainability. Sustainability means leaving a planet at least as diverse, healthy, and beautiful as it was given to all of us. Just as a forest can occupy a place for millennia and yet leave the land richer, not poorer, our "footprint" should be a benefit not a detriment. We humans will forever need built environments and will always impact the places and ecosystems where we are located; our legacy must be an improvement in overall social and ecological systems. By 2040, the majority of the buildings in America will have been designed and built in the twenty-first century. These buildings should be designed to require little outside energy or to produce net energy, to use local products 
and conserve water, and to be accessible by safe, healthy transit. We have huge tasks ahead in repairing the degradation that has already occurred to this planet's wetlands, forests, oceans, atmosphere, and people. Giving our grandchildren a ruined planet could in some ways be considered a form of child abuse. Yet, it may be that all we can accomplish in our lifetimes is a redirecting of the current negative trajectory of human planetary damage. The care of the planet must start with sustainability-not just environmental but also social and economic.

We intend this book for students and other persons interested in obtaining a deeper knowledge of how the built environment affects health. Although we have used references and extensive data to substantiate our points, we have worked to keep the text free of technical jargon. When one is addressing the subject of built environment and health, much of the work-and a big part of the fun-involves crossing multiple disciplines. To incorporate knowledge from many disciplines in this book, we sought chapter contributions from colleagues with training and expertise in public health, epidemiology, urban planning, architecture, landscape architecture, law, psychology, public policy, political science, industrial hygiene, and other fields.

This book outlines the challenges the United States faces and describes a vision of healthy, sustainable communities where people can walk to shops, schools, friends' homes, and transit stations; where individuals can interact with neighbors and admire trees, plants, and other natural features; where the air and water are clean; and where there are parks and play areas for children, gathering places for teens and the elderly, and convenient work and recreation areas for all. We envision that every urban and suburban lake, stream, and river will be swimmable and fishable and its banks walkable. Children and adults will be physically active by choice when they have safe places to walk or bicycle or otherwise enjoy the outdoors. All Americans will have the opportunity to age in place, with dignity and surrounded by community. This is not a mere dream. This nation had places like this in many cities before World War II. We do not seek to reduce personal choices, rather we argue for more choices. The old US cities that people enjoy so much, such as Annapolis, Boston, and San Francisco, offer both density and quality of life. This book is our effort to lay out how the built environment affects everyone and how by building with people's health and future in mind, every community in America can improve its residents' quality of life.

\section{References}

Administration on Aging. 2010. Aging Statistics. http://www.aoa.gov/aoaroot/aging_statistics/ index.aspx 
CDC (Centers for Disease Control and Prevention), National Center for Health Statistics. 2009. Prevalence of Overweight, Obesity and Extreme Obesity among Adults: United States, Trends 1960-62 through 2005-2006. http://www.cdc.gov/nchs/data/hestat/overweight/ overweight_adult.htm

CDC (Centers for Disease Control and Prevention). 2010a. Childhood Overweight and Obesity. http://www.cdc.gov/obesity/childhood/.

CDC (Centers for Disease Control and Prevention). 2010b. US Obesity Trends, by State 19852009. http://www.cdc.gov/obesity/data/trends.html

Committee on Environmental Health. 2009. "The Built Environment: Designing Communities to Promote Physical Activity in Children." Pediatrics 123 (6): 1591-98.

Dumbaugh, E. 2005. "Safe Streets, Livable Streets." Journal of the American Planning Association 71 (3): 283-300. http://www.informaworld.com/smpp/content $\sim \mathrm{db}=\mathrm{all} \sim$ content=a787370026

Ewing, R., K. Bartholomew, S. Winkelman, J. Walters, and D. Chen. 2008. Growing Cooler: Evidence on Urban Development and Climate Change. Washington, DC: Urban Land Institute.

Ewing, R., R. Schieber, and C. V. Zegeer. 2003. "Urban Sprawl as a Risk Factor in Motor Vehicle Occupant and Pedestrian Fatalities." American Journal of Public Health 93 (9): 1541-45. http://ajph.aphapublications.org/cgi/reprint/93/9/1541.pdf

Flegal, K. M., M. D. Carroll, and C. L. Ogden. 2010. "Prevalence and Trends in Obesity among US Adults, 1999-2008." JAMA 303 (3): 235-41.

Frank, L., J. F Sallis, T. Conway, J. Chapman, B. Saelens, and W. Bachman. 2006. "Many Pathways from Land Use to Health: Walkability Associations with Active Transportation, Body Mass Index, and Air Quality." Journal of the American Planning Association 72 (1): 75-87.

Frank, L., B. Stone, and W. Bachman. 2000. "Linking Land Use with Household Vehicle Emissions in the Central Puget Sound: Methodological Framework and Findings." Transportation Research Part D-Transport and Environment 5 (3): 173-96.

Kuo, F. E., and A. F. Taylor. 2004. "A Potential Natural Treatment for Attention-Deficit/Hyperactivity Disorder: Evidence from a National Study." American Journal of Public Health 94 (9): 1580-86. http://ajph.aphapublications.org/cgi/reprint/94/9/1580.

LaChapelle, U., and L. D. Frank. 2009. "Transit and Health: Mode of Transport, EmployerSponsored Public Transit Pass Programs, and Physical Activity." Journal of Public Health Policy 30, suppl. 1: 573-94. http://www.palgrave-journals.com/jphp/journal/v30/nS1/pdf/ jphp200852a.pdf

Litman, T. 2010. Are Vehicle Travel Reduction Targets Justified? Evaluating Mobility Management Policy Objectives Such as Targets to Reduce VMT and Increase Use of Alternatives Modes. Victoria, BC: Victoria Transport Policy Institute. http://www.vtpi.org/vmt_red.pdf

MacDonald, J. M., R. J. Stokes, D. A. Cohen, A. Kofner, and G. K. Ridgeway. 2010. "The Effect of Light Rail Transit on Body Mass Index and Physical Activity." American Journal of Preventive Medicine 39 (2): 105-12. http://download.journals.elsevierhealth.com/pdfs/jour nals/0749-3797/PIIS0749379710002977.pdf

Narayan, K. M., J. P. Boyle, T. J. Thompson, S. W. Sorenson, and D. F. Williamson. 2003. "Lifetime Risk of Diabetes Mellitus in the United States." JAMA 290 (14): 1884-90. http://jama.ama -assn.org/cgi/content/full/290/14/1884.

Olfson, M., M. J. Gameroff, S. C. Marcus, and P. S. Jensen. 2003. "National Trends in the Treatment of Attention Deficit Hyperactivity Disorder." American Journal of Psychiatry 160: 1071-77.

Olfson, M., and S. C. Marcus. 2009. "National Patterns in Antidepressant Medication Treatment." Archives of General Psychiatry 66 (8): 848-56.

Orszag, P. R., and R. Ellis. 2007. "The Challenge of Rising Health Care Costs-A View from the Congressional Budget Office." New England Journal of Medicine 357: 1793-95.

Texas Transportation Institute. 2009. Congestion Trends-Wasted Hours (Annual Delay per Traveler, 1982-2007). College Station: Texas A\&M University System, Texas Transportation Institute. http://mobility.tamu.edu/ums/congestion_data/tables/national/table_4.pdf 
US Census Bureau. 2005. "Americans Spend More than 100 Hours Commuting to Work Each Year, Census Bureau Reports." http://www.census.gov/newsroom/releases/archives/american _community_survey_acs/cb05-ac02.html

US DOT (US Department of Transportation), Federal Highway Administration. 2008. Congestion

Pricing. http://ops.fhwa.dot.gov/publications/fhwahop08039/fhwahop08039.pdf 